\title{
Precisamos falar sobre racismo e desigualdade social na academia e no campo editorial brasileiros
}

Dol

http://dx.doi.org/10.11606/ 2179-0892.ra.2020.174716
Laura Moutinho

Universidade de São Paulo | Faculdade de Filosofia, Letras e Ciências

Humanas | Departamento de Antropologia| São Paulo, SP, Brasil |

Imoutinho@usp.br | https://orcid.org/0000-0001-6479-2711
Pedro de Niemeyer Cesarino

Universidade de São Paulo | Faculdade de Filosofia, Letras e Ciências

Humanas | Departamento de Antropologia São Paulo, SP, Brasil | pedrocesarino@gmail.com | https://orcid.org/0000-0002-4158-7712

Sylvia Caiuby Novaes

Universidade de São Paulo | Faculdade de Filosofia, Letras e Ciências

Humanas | Departamento de Antropologia | São Paulo, SP, Brasil |

scaiuby@usp.br | https://orcid.org/0000-0002-7415-2010

Assumir a racialização que sempre marcou o lugar do outro é assumir o aspecto fundamentalmente relacional da produção de sentido, não apenas de identidade, mas sobretudo de conhecimento. Não é mais possível às ciências sociais brasileiras habitarem este lugar da universalidade ocidental - lugar que nos engloba, mas não nos pertence.

Luena Nascimento Nunes Pereira

"I can't breathe...". No auge da pandemia provocada pela Covid-19, uma doença sistêmica provocada pelo SARS-CoV-2, um vírus altamente letal e que provoca dificuldades respiratórias, o mundo ouviu a frase sussurrada por George Floyd, um homem negro, em Minnesota, pouco antes de morrer sob os joelhos de um policial branco.

25 de maio de 2020. Esse dia e essa frase ecoam o desespero de mais de 70 pessoas em diferentes momentos que, pelo que nos informa o jornal estadunidense New York Times, vocalizaram essas palavras antes de morrer sob a custódia da polícia. Mais da metade eram homens negros'.

\#SayHerName é o mote da campanha, iniciada pelo African American Policy Forum, para chamar atenção não apenas à violência assassina da polícia contra muIheres e meninas negras, mas para acionar sua memória, verbalizando seus nomes e oferecendo apoio a familiares².

"Enough Is Enough..." tem sido uma das frases proferidas durante as manifesta-

2 | https://aapf.org/sayhername Último acesso 27/08/2020. ções que tomaram as ruas, inicialmente, nos Estados Unidos e, posteriormente, no mundo, contra o racismo.

Black Lives Matter. Das ruas, as manifestações mostraram força pela abrangência com que se espraiaram por diferentes cenários em escalas jamais vistas. Após o assassinato de Ceorge Floyd, já foram reportadas mais de 7.700 manifestações associadas ao movimento criado em 2013, o Black Lives Matter, em 2 mil localidades nos Estados Unidos.

1 https://www.nytimes.com/ interactive/2020/06/28/us/icant-breathe-police-arrest.html Último acesso 27/08/2020. 
Em junho, não sem surpresa, o mercado das publicações científicas estadunidense parou por um dia: pesquisadoras e pesquisadores e editorias de periódicos suspenderam suas atividades protestando contra o racismo na academia. O trabalho cientifico e suas formas de divulgação foram inquiridos pela maneira como se constroem, a partir de uma estrutura de privilégios que exclui negros e negras e outras pessoas não brancas.

O movimento \#ShutDownSTEM (STEM - sigla em inglês que agrupa ciência, tecnologia, engenharia e matemática) conclamava que seus profissionais refletissem sobre o racismo em suas respectivas áreas e que procurassem criar medidas contra sua perpetuação.

De acordo com a Nature, que aderiu ao movimento, a campanha "Strike for Black Lives" envolveu mais de 5 mil pesquisadores e pesquisadoras, associações científicas, universidades e editoras e editores. Esse processo de reflexividade não se limitou aos Estados Unidos. Três editoras científicas engrossaram os protestos, comprometendo-se em revisar suas formas de agir, pensar e se organizar, são elas: Hachette, Simon \& Schuster e Penguin Random House.

Esse movimento político, científico e editorial tampouco ficou restrito ao mundo anglófono ou do Norte Global. No Brasil, a maioreditora do país, a Companhia das Letras, adotou uma série de medidas no sentido de combater o racismo, que também a estrutura, criando um cargo de "editor da diversidade", abrindo espaço para a diversidade racial, étnica, de orientação sexual e de gênero de suas publicações, autores e autoras. Espera-se, com essa nova política corporativa, ampliar e rever "linguagens, discursos e personagens [...] excluídos do mundo editorial", conforme o historiador que ocupa o novo cargo 3 .

Um movimento que se espalha pelo globo não pode nos enganar em termos geopolíticos. A realidade do racismo se estrutura diferentemente em cada contexto nacional, como vem sendo destacando reiteradamente (Moutinho 2004, 2010; Lopes \& Moutinho 2012). Os Estados Unidos, país produtor de desigualdade em escala mundial, funcionam como exemplo apenas até certo ponto. A estrutura de privilégios no Brasil obedece a outras lógicas, inclusive na academia.

Ainda que, neste momento, soe-nos fundamental enfrentar inclusive o racismo científico, vale lembrar que mesmo perspectivas acadêmicas reconhecidas como a eugenia não foram apropriadas de modo unívoco em cada contexto nacional e, especialmente, no que hoje chamamos de Sul Clobal: as apropriações sul-africanas e brasileiras e a não pregnância nesses contextos de argumentos ventilados no Norte, funcionam para endossar a reflexão aqui proposta (Moutinho, 2004; Moutinho \& Carrara, 2010).

Neste debate, é fundamental lembrar que no Brasil, que foi um dos últimos países a abolir a escravatura, pessoas que se autodeclaram pretas e pardas constituem quase $56 \%$ da população, segundo dados do IBCE 4 .

3 Consultar https://www. geledes.org.br/companhiadas-letras-tenta-combaterracismo-nomeando-editorde-diversidade/, acesso em30 de agosto de 2020 tabela/6403, acesso em 30 de agosto de 2020 . 
Concomitantemente, a presença dessa maioria da população nas universidades, nos postos de liderança no trabalho, entre parlamentares e no Judiciário é desproporcionalmente reduzida. O que chama atenção, comparativamente, é sua vulnerabilidade, especialmente a de jovens negros frente às forças policiais, à criminalização da raça e da pobreza no Brasil, bem como à recente a tragédia da Covid-19.

São devastadoramente numerosos os casos de racismo no Brasil, tão silenciados e invisibilizados. Momentos de crise, como o suscitado pelo assassinato cruel de George Floyd, aliado ao negacionismo dos governantes com relação à pandemia da Covid-19, convocam renovadas ações e reflexões.

Tudo isso, que repercutiu tanto - mas não apenas - em língua inglesa e na produção científica e editorial estadunidense, poderia ter acontecido no Brasil. Mas não aconteceu. Ou aconteceu? George Floyd foi morto nos Estados Unidos. São muitos os Ceorge Floyd que padecem sob as mãos da brutalidade policial nas periferias e favelas brasileiras. Então, foi no Brasil o assassinato? Foi. Mas, aqui, ninguém se considera racista: "todo mundo" tem "amigos negros". Quem não tem um ancestral negro ou negra? Estamos no país da miscigenação, certo? Será que um traço fenotípico, um acessório, bastam para performatizar o antirracismo? Palavras e expressões mostram que são tantos os enganosos sinais do... auto-engano. Não foi no Brasil que George Floyd morreu. Mas o país mata com gestos, palavras e políticas muitas pessoas negras e, especialmente, as mais pobres.

E você, leitor ou leitora, se considera racista? O que é racismo? Quem pode ser considerado racista? Essas não são perguntas banais no Brasil. Toda uma geração de acadêmicas, acadêmicos e militantes se esforçou para mostrar que "existia racismo no Brasil". Se Florestan Fernandes trouxe os pobres e os negros para a teoria social, produzindo, concomitantemente, uma nova representação de nação - agora marcada pelo racismo e pela exclusão -, outros e outras, a partir da década de 1980, começaram a forçar as estruturas políticas e epistemológicas de seus campos de atuação, como fizeram Lélia Conzalez, Beatriz Nascimento, Eduardo de Oliveira e Oliveira, Sueli Carneiro, entre tantas e tantos.

Luena Nascimento Nunes Pereira abre o volume atual inquirindo essas estruturas na academia brasileira e, em especial, na produção antropológica. Em reflexão intitulada "Alteridade e raça entre África e Brasil: branquidade e descentramentos nas ciências sociais brasileiras" - fruto da conferência proferida no $43^{\circ}$ Encontro Anual da ANPOCS, realizado em Caxambu-MG, em 2019, que a Revista de Antropologia tem o privilégio de publicar-, a autora problematiza a construção racializadora do "outro" na produção das Ciências Sociais.

A eleição do presidente Jair Bolsonaro, a gramática moral que informa sua ascensão e a complexa produção de subjetividades políticas, engajamento comunitário e práticas de voto entre moradores das periferias da zona sul de São Paulo são analisados no artigo intitulado "Between 'Us' and 'Them': Political Subjectivities 
in the Shadows of the 2018 Brazilian Election", de autoria de Charles Klein, Milena Mateuzi Carmo e Alessandra Tavares. Interessante notar como o desencanto com a política institucional não elide a prática política e o engajamento na vida cotidiana.

O tema do racismo é abordado a partir de outro viés e outro contexto por Antonia Olmos Alcaraz no artigo "Racismo, racialización e inmigración: aportaciones desde el enfoque de(s)colonial para el análisis del caso español". No texto, a autora provoca o leitor e a leitora a pensar sobre os processos de racialização entre imigrantes marroquinos em espaço escolar e procura contribuir para o debate mais amplo a partir de um aporte de(s)colonial.

Exclusão e erotismo são debatidos no artigo “'Alguém a fim?': uma etnografia on-line em salas de bate-papo na fronteira Brasil-Bolívia" de autoria de Carla Cristina de Souza e Tiago Duque. Nesse texto, elaborado a partir de uma etnografia em ambiente virtual e região de fronteira (Brasil-Bolívia), o público leitor se aproxima das relações de gêneros dissidentes e de sexualidades disparatadas.

A temporalidade complexa do processo transexualizador é analisada por Camilo Braz e Anderson Santos Almeida no artigo "Espera, Paciência e Resistência - reflexões antropológicas sobre transexualidades, curso da vida e itinerários de acesso à saúde". A análise se desenrola seguindo dois contextos da cidade de Goiânia com mulheres e homens trans que acessam a possibilidade de atuar sobre seus corpos por meio do Sistema Único de Saúde (SUS). Interessante notar como a "espera", categoria central da análise, articula e produz corpo, gênero e vida.

Com base em etnografia realizada no Instituto Municipal de Assistência à Saúde Nise da Silveira, no Rio de Janeiro, Felipe Magaldi oferece reflexões sobre o uso de psicofármacos em instituições psiquiátricas que atendem pessoas em situação social precarizada no artigo "Nas tramas da poção mágica: psicofármacos e criatividade em um hospital psiquiátrico do Rio de Janeiro". É assim que discussões sobre biopolítica são contrastadas com os agenciamentos e vetores de relações produzidos pelo uso dos fármacos, que deixa de ser compreendido de maneira puramente isolada.

Ainda no que se refere ao acesso ao sistema público de saúde no Brasil, Valdir Aragão do Nascimento explora, em "Subvertendo a Ordem: Os Indocumentados e as Estratégias de Acesso à Saúde na fronteira de Ponta Porã/BR e Pedro Juan Caballero/ PY", as estratégias dos indocumentados em tal região de fronteira, que mobilizam redes de solidariedade e relações ambíguas de confiança e legalidade.

Em “Um lugaronde se achar. Deslocamentos e rituais entre os Cuarani do Chaco boreal paraguaio", María Eugenia Domínguez mostra como o Chaco é transformado em um lugar guarani através da ação ritual e da produção estética, oferecendo assim, por meio de uma etnografia detalhada, novos elementos para a compreensão das redes de relação e concepções do espaço para tais coletivos, que não perfazem uma totalidade coesa e hierárquica.

Ainda no que se refere às redes ameríndias de relação, Luis Cayón, em "Disputas 
fraternas e chefia bicéfala: hierarquia e heterarquia no Alto Rio Negro", examina as relações de competição e de poder entre irmãos nos complexos sistemas sociais de tal região. O estudo oferece elementos importantes para a compreensão das relações entre chefia e xamanismo nas terras baixas sul-americanas, tendo em vista as polêmicas em torno da possibilidade ou não de produção do Estado na Amazônia. Tema candente da etnologia americanista, o debate sobre hierarquia entre sociedades indígenas deve ainda oferecer contrapontos interessantes, na medida mesma de sua alteridade radical, para a compreensão da conturbada política brasileira e o presente estado de crise da democracia.

Fecham o número duas resenhas, que, daqui em diante, publicamos com fotos das capas das obras analisadas. Lorena Córdoba discute o livro de Isabelle Combès, Para una etnohistoria de los últimos tobas de Bolivia / Hijos del Pilcomayo. Los últimos tobas de Bolivia e Paulo Büll resenha o livro de Uirá Garcia, Resistir no céu, viver na Terra. AwáCuajá. Crônicas de Caça e Criação.

Por fim, assinalamos que a Revista de Antropologia, que sempre foi comprometida com o acesso aberto, inicia publicação continuada a partir do número atual. Sendo o periódico mais antigo da área de Antropologia, a Revista adere ao movimento de reflexividade, trabalhando no sentido de rever a estrutura racista e desigual na qual se insere tanto em relação à lógica de publicações quanto de seu quadro de colaboradoras e colaboradores. Esse compromisso vem sendo aprimorado no sentido de minorar o sofrimento humano produzido por estruturas de opressão e, concomitantemente, pretendemos, nesse processo, contribuir para a construção de uma sociedade que não esteja baseada no ódio, tampouco em sua disseminação. Perguntamos, assim, às leitoras e aos leitores deste periódico: em que sociedade vocês desejam viver?

\section{REFERÊNCIAS BIBLIOGRÁFICAS}

ALCARAZ, Antonia Olmos. 2020. Racismo, Racialización E Inmigración. Aportaciones desde el enfoque de(s)colonial para el análisis del caso español. Revista De Antropologia 63 (2): e170980. DOI: https:// doi.org/10.11606/2179-0892.ra.2020.170980

BRAZ, Camilo; ALMEIDA, Anderson Santos. 2020. Espera, Paciência E Resistência. Reflexões antropológicas sobre transexualidades, curso da vida e itinerários de acesso à saúde. Revista De Antropologia 63 (2): e170813. DOI: https:// doi.org/10.11606/2179-0892.ra.2020.170813
CAYÓN, Luis. 2020. Disputas Fraternas E Chefia Bicéfala. Hierarquia e heterarquia no Alto Rio Negro. Revista De Antropologia 63 (2): e151160. DOI: https://doi. org/10.11606/2179-0892.ra.2020.171366

DOMÍNGUEZ, María Eugenia. 2020. Um Lugar Onde Se Achar. Deslocamentos e rituais entre os Guarani do Chaco boreal paraguaio. Revista De Antropologia 63 (2): e157328. DOI: https:// doi.org/10.11606/2179-0892.ra.2020.172072 
KLEIN, Charles; CARMO, Milena Mateuzi; TAVARES, Alessandra. 2020. Entre "nós" e "eles". Subjetividades políticas nas sombras das eleições brasileiras de 2018. Revista de Antropologia 63 (2): e160722. DOI: https:// doi.org/10.11606/2179-0892.ra.2020.171482

LOPES, Pedro \& MOUTINHO, Laura. 2012 . Uma Nação de Onze Línguas? Diversidade social e linguística nas novas configurações de poder na África do Sul. Revista Tomo (UFS), v. 20, p. 27-57. https:// doi.org/10.21669/tomo.voi20.859

MAGALDI, Felipe. 2020. Nas Tramas Da Poção Mágica. Psicofármacos e criatividade em um hospital psiquiátrico carioca. Revista De Antropologia 63 (2): e146007. DOI: https:// doi.org/10.11606/2179-0892.ra.2020.171315

MOUTINHO, Laura. 2014. Diferenças e desigualdades negociadas: raça, sexualidade e gênero em produções acadêmicas recentes. Cadernos Pagu, (42), 201-248. https://doi. org/10.1590/0104-8333201400420201

Moutinho, Laura \& Carrara, Sérgio. 2010. Apresentação. Cadernos Pagu, (35), 9-35. https://doi.org/10.1590/ S0104-83332010000200002
MOUTINHO, Laura. 2004. Razão, "Cor" e Desejo: Uma Análise Comparativa sobre Relacionamentos Afetivo-Sexuais "inter-raciais" no Brasil e na África do Sul. São Paulo: UNESP.

NASCIMENTO, Valdir Aragão do. 2020. Subvertendo a Ordem. Os Indocumentados e as Estratégias de Acesso à Saúde na fronteira de Ponta Porã/BR e Pedro Juan Caballero/PY. Revista De Antropologia 63 (2): e161823. DOI: https://doi. org/10.11606/2179-0892.ra.2020.170816

PEREIRA, Luena Nascimento Nunes. 2020. Alteridade e Raça entre África e Brasil. Branquidade e descentramentos nas ciências sociais brasileiras. Revista De Antropologia 63 (2): e169457. DOI: https://doi. org/10.11606/2179-0892.ra.2020.170727

SOUZA, Carla Cristina de; DUQUE, Tiago. Alguém a fim? Uma etnografia on-line em salas de bate-papo na fronteira Brasil-Bolívia. Revista de Antropologia 63 (2): e155710. DOI: https:// doi.org/10.11606/2179-0892.ra.2020.170814

Recebido em 25 de agosto de 2020. Aceito em 27 de agosto de 2020. 